\title{
Cidade dos Bits: Um game para auxiliar no Aprendizado dos Fundamentos da Ciência da Computação a Nível Médio
}

\author{
Tatyane S. C. da Silva ${ }^{1}$, Jeane C. B. de Melo ${ }^{1}$ \\ ${ }^{1}$ Universidade Federal Rural de Pernambuco (UFRPE) \\ Rua D. Manoel de Medeiros, s/n, Dois Irmãos - CEP: 52171-900 - Recife - PE - Brasil \\ \{taty.calixto, jeane.ufrpe\}@gmail.com
}

\begin{abstract}
The use of computers as a tool in the school environment is increasingly used as a strategy to support the teaching-learning process. The teaching of the fundamentals of computer science, in its turn, is important to bring the scientific knowledge to elementary school students. In this context, educational games can promote the teaching of computing in a ludic, motivating and fun way. This article proposes a digital game that helps the teaching of Computer Science concepts in the high school.

Resumo. O uso da informática como ferramenta no ambiente escolar é cada vez mais difundido como estratégia para auxiliar no processo de ensinoaprendizagem. $O$ ensino dos fundamentos da Ciência da Computação, por sua vez, é importante para aproximar o conhecimento científico dos alunos do ensino básico. Nesse contexto, os jogos educacionais podem promover o ensino da Computação de forma lúdica, motivadora e divertida. Este artigo objetiva propor um jogo digital que auxilie o ensino dos conceitos de Ciência da Computação no ensino médio.
\end{abstract}

\section{Introdução}

A presença cada vez mais frequente da informática no cotidiano provoca discussões e debates sobre o papel da escola moderna no uso e ensino de dispositivos tecnológicos como objeto da formação do indivíduo e como ferramentas que auxiliam o processo de ensino-aprendizagem. Apesar da diversidade de equipamentos computacionais é pequena a parcela da população que possui conhecimento sobre os fundamentos destes dispositivos.

Uma vez que um dos objetivos da educação consiste em propiciar a compreensão do mundo através do ensino das Ciências, a escola precisa mudar para integrar e aproximar o estudante do mundo científico e tecnológico que o circunda (PCN 2000). O desconhecimento sobre o mundo que nos cerca pode limitar significativamente o desenvolvimento e a relação dos educandos com os demais e mesmo com o ambiente.

Segundo Tenório (2001), um ponto fundamental para a formação crítica do discente é a compreensão conceitual das máquinas e computadores, a qual deve ser feita de modo que haja um desvendamento da relação entre os procedimentos mecânicos e a lógica presente no desenvolvimento e utilização das aplicações envolvendo tais dispositivos. Assim, o ensino da Computação como Ciência pode melhorar o aprendizado escolar, através do desenvolvimento do raciocínio lógico. 
Porém, transpor as metodologias tradicionais utilizadas no ensino superior para o ensino médio não é suficiente, uma vez que alguns fatores, já observados em estudantes universitários, corroboram para altos índices de reprovação em disciplinas que envolvem os fundamentos, podem ser replicados para alunos do segundo grau. Assim, é importante buscar novas metodologias de ensino que permitam ensinar os conceitos de Ciência da Computação a nível médio de uma forma mais atraente e lúdica.

Nessa perspectiva, jogos podem ser utilizados para consolidar o aprendizado de maneira lúdica, divertida e natural. Os jogos propiciam o aprendizado dos discentes num contexto, onde o conhecimento será aplicado de forma significativa, podendo promover o desenvolvimento de habilidades tais como comunicação, interação, colaboração e resolução de problemas, muito relevantes no processo de aprendizado (Koster 2004).

Considerando ainda o processo de aprendizado é necessário observar a motivação do aluno, fator que o leva a persistir na resolução de um problema, na conclusão de uma atividade e mesmo no curso escolhido (Scaico et al 2011). Segundo Koster (2004) deve-se acabar com a distância entre aprendizagem e diversão, trabalho e jogo. A diversão deve ser tratada com tal importância na interface de um jogo educativo que o aprendizado possa ocorrer de forma atraente e sem pressão (Scaico et al 2011).

Diante deste panorama, o presente trabalho tem por objetivo propor um jogo digital intitulado Cidade dos Bits, destinado ao ensino dos fundamentos da Ciência da Computação no Nível Médio, utilizando uma metodologia de ensino baseada em jogos. O game traz elementos de aprendizagem significativa, buscando explorar os conhecimentos do jogador sobre fundamentos de Computação e sua habilidade com jogos, desmistificando a computação de maneira motivadora e divertida, difundindo, ainda, o pensamento computacional. Este artigo está organizado da seguinte forma: na Seção 2, a metodologia de aprendizado baseado em jogos digitais é apresentada; na Seção 3 são abordados os requisitos do jogo; a proposta do jogo é tratada na Seção 4; na Seção 5 são feitas considerações finais e proposta de trabalhos futuros.

\section{Fundamentação Teórica: Aprendizagem Baseada em Jogos Digitais}

A afirmação de que a tecnologia da informação mudou a maneira de viver e se relacionar das pessoas é consensual, influenciando também o modo de aprender dos alunos. Estudos afirmam que os estudantes por volta de vinte anos têm mais experiência com jogos do que com a leitura (Oblinger 2004).

De um modo geral, os jovens apresentam desinteresse pelos conteúdos curriculares em contraste com a enorme motivação no ato de jogar. Isso pode ser explicado pelo fato de que os jogos trazem desafios e diversão enquanto as atividades escolares são classificadas por eles como tediosas. Essa postura dos alunos pode refletir o interesse crescente pelo aprendizado informal, disponível no mundo virtual, que permite ao estudante obter informações através da internet e construir de forma autônoma seu conhecimento. Nesse contexto, o ambiente dos jogos também pode ser classificado como informal, visto que estes propiciam um espaço multissensorial e de intenso envolvimento por parte do aluno (Sheppard 2000).

A motivação inerente dos jovens pelos jogos pode ser uma aliada ao ensino quando utilizada em conjunto com conteúdos curriculares. Segundo Prensky (2003), 
essa combinação é chamada de "Aprendizagem baseada em Jogos Digitais", cuja sigla em inglês é DGBL - Digital Game-Based Learning. Através dos jogos educacionais, acredita-se promover um aprendizado mais centrado no aluno, mais motivador e divertido e, portanto, mais eficaz (Prensky 2003).

Alguns estudos mostram que a abordagem DGBL é mais eficaz no processo de aprendizagem do que a utilização da metodologia tradicional, contribuindo de maneira positiva para o conhecimento do assunto devido à forma prazerosa que este é ensinado (Papastergiou 2009).

\section{Requisitos do jogo}

O jogo Cidade dos Bits é resultado de um projeto que envolve o desenvolvimento de metodologias inovadoras para o ensino dos fundamentos da Computação no Ensino Médio, que foi iniciado através do uso da abordagem Computer Science Unplugged (Bell e Fellows 2011) para introduzir conhecimentos iniciais sobre a Computação e seus fundamentos.

O game Cidade dos Bits tem o intuito de fornecer desafios que explorem inicialmente a familiarização com conceitos básicos da Ciência da Computação como números binários, algoritmos e teoria da computação.

O jogo foi especificado de acordo com os seguintes requisitos:

i. Jogabilidade: o game apresenta desafios que exigem habilidades do jogador como: velocidade, conseguir pontuação e descoberta.

ii. Usabilidade: a cada desafio alcançado com sucesso o jogador terá um feedback para saber em que distância está do objetivo final.

iii. Pedagógicos: os fundamentos da computação são abordados previamente através de aulas lúdicas, seguindo a linha proposta em Computer Science Unplugged (Bell e Fellows 2011). Se o jogador perder em algum momento do desafio, terá a possibilidade de jogar novamente de onde parou. Desta forma, levam-se em consideração as etapas concluídas com sucesso, bem como o conhecimento adquirido evitando, assim, a desmotivação no caso de ter que iniciar o jogo do começo. O jogo traz, portanto, o conceito de que o erro faz parte do aprendizado: "o erro não é fonte de castigo, mas suporte para o crescimento" Luckesi (2002).

iv. Portabilidade: o jogo está implementado para Computadores com Sistema Operacional (S.O.) Windows 7 qualquer versão.

\section{Proposta do jogo}

O jogo intitulado Cidade dos Bits, visa promover o ensino-aprendizagem dos fundamentos da Ciência da Computação a nível médio. Composto de sucessão de desafios, que consistem em atingir uma pontuação em jogos propostos e responder questões sobre fundamentos de Computação em forma de quiz, este jogo transporta o jogador para um mundo digital e tecnológico, e o desafia a salvar essa cidade das garras do inimigo, o hacker, o qual quer governar a Cidade dos Bits. O objetivo final do hacker é banir o Sistema Operacional (S.O.) Romanon que governa a Cidade dos Bits e dessa forma controlar o mundo dos computadores. Se o hacker conseguir governar a cidade dos Bits ele será o detentor de toda a tecnologia, colocando todos os habitantes do mundo em perigo. 
O jogador deve decifrar os enigmas enviados pelo hacker que desafiará seus conhecimentos sobre os fundamentos da Ciência da Computação. Cada enigma desvendado enfraquece o domínio do hacker sobre a cidade dos Bits. O jogador passará por níveis que testarão seus conhecimentos em Computação e sua habilidade em jogos dos anos 80, enviados pelo hacker para distrair o jogador do seu objetivo final na Cidade dos Bits. No decorrer do jogo os enigmas ficarão mais complexos. O jogador, ao ser bem sucedido nos desafios, gera um código secreto de segurança que dificulta a estadia do hacker na Cidade dos Bits, deixando a cidade mais protegida e fortalecendo Sistema Operacional. Ao completar todas as etapas o S.O. ficará mais forte e vencerá o hacker.

Os personagens que vão interagir com o jogador são: Romanon, o Sistema Operacional, que pedirá ajuda ao jogador para salvar a Cidade dos Bits do ataque do hacker. Romanon aparecerá em momentos críticos da missão do jogador para dar dicas, ajudá-lo e orientá-lo nos enigmas. Primeiramente o jogador será desafiado no Tetris. $\mathrm{O}$ jogo, popular nos anos 80, consiste em empilhar polígonos formados a com 3 ou 4 quadradinhos, em formatos diversos, que descem a tela de modo a completar linhas horizontais. Ao perceber que o jogador está conseguindo avançar em pontos no jogo Tetris, o hacker fará o possível para evitar que este atinja o objetivo final e irá colocar enigmas no caminho do jogador.

Os enigmas iniciais abordam números binários, apresentando perguntas a serem respondidas na forma de quiz. Inicialmente, as perguntas são propostas sem marcar o tempo de resposta. Na medida em que o jogador avança, as perguntas passam a ter um limite de tempo para serem respondidas. O primeiro nível contará com três perguntas. Se estas forem respondidas corretamente, o jogador volta à tela do Tetris, executando-o em um nível de dificuldade maior. Uma vez atingida a pontuação designada pelo hacker, o jogador passa para a etapa do jogo da memória de números binários, também proposto no atual trabalho. Neste jogo, o desafio é encontrar pares de cartas similares, combinando números binários com seu correspondente em número decimal, testando os conhecimentos do jogador nesse tópico. O jogo consiste de cinco pares de cartas e o jogador disporá de 3 minutos para acertar todos os pares correspondentes. Se o jogador não conseguir acertar todos os pares nesse tempo, este terá a oportunidade de tentar novamente, partindo de onde parou. Passando por esses enigmas, o jogador vence, salvando a Cidade dos Bits do hacker. O hacker será neutralizado e ficará latente por algum tempo.

\section{Considerações Finais e Trabalhos Futuros}

As abordagens sobre os fundamentos da computação muitas vezes são limitadas ao uso da informática apenas como ferramenta. Mesmo sendo atrativo, este enfoque restringe a Ciência da Computação como competência de uso adequado de equipamentos e programas computacionais. Contudo, a compreensão analítica e crítica do computador não estão limitadas ao seu uso como instrumento, mas, principalmente, pelo entendimento dos aspectos conceituais dos seus fundamentos (Tenório 2001).

Nesse contexto, o aprendizado dos fundamentos da Computação no ensino médio através do jogo pode trazer um entretenimento, com fins educacionais, como uma forma de motivação, despertando o interesse dos discentes por essa área, se diferenciando assim das abordagens tradicionais, que dificultam a abstração dos 
conceitos básicos dessa Ciência. O presente trabalho buscou contribuir com este tipo de abordagem, propondo um jogo que trate de conceitos de fundamentos da Computação e que aborde o assunto de maneira lúdica e motivadora, de modo que possa ser aplicado para alunos do ensino médio. O Jogo aqui apresentado explora um conjunto inicial de tópicos referentes a esta área de conhecimento, porém pretende-se abranger mais conceitos relacionados a Ciência da Computação.

Uma diretiva futura é permitir que o jogador escolha o tipo de jogo que pretende ser desafiado. A versão atual desafia o usuário com jogos dos anos 80. Em versões posteriores, pretende-se inserir opção de escolha de outros tipos de jogos como: quiz, simulação de algoritmos e Sistema Operacional, ou lógica como desafio. As questões sobre fundamentos da Computação também podem ser ampliadas incluindo desafios que abranjam outros tópicos dessa Ciência, envolvendo, por exemplo, o desenvolvimento de pequenos códigos como requisito para que o usuário passe para a etapa seguinte. A versão atual do jogo Cidade dos Bits será levada para alunos da rede pública de ensino médio a fim de observar a aceitação do formato do jogo.

\section{Agradecimentos}

Este trabalho foi realizado com o apoio do Programa Institucional de Bolsa de Iniciação à Docência-PIBID, da CAPES-Coordenação de Aperfeiçoamento de Pessoal de Nível Superior - Brasil.

\section{Referências}

Bell,T.,Witten,I.H. e Fellows,M. (2011). "Computer Science Unplugged. Ensinando Ciência da Computação sem o uso do computador". Tradução por: Luciano Porto Barreto. Disponível em: http://csunplugged.org/books.

Koster, R. (2004). Theory of fun for game design. Scottsdale: Paraglyph, p. 80-99.

Luckesi, C. (2002). Avaliação da Aprendizagem Escolar. 13.ed. São Paulo: Cortez.

Oblinger, D. (2004). The next generation of educational engagement. Journal of Interactive Media in Education, 2004(8), 1-18.

Papastergiou, M. (2009). "Digital Game-Based Learning in high school Computer Science education: Impact on educational effectiveness and student motivation". Computers \& Education 52 1-12. Disponível em: http://www.sciencedirect.com/science/article/pii/S0360131508000845

PCN (2000). "Parâmetros Curriculares Nacionais (Ensino Médio) - Parte II: Linguagens, Códigos e sua Tecnologias".

Prensky, M. (2003). Digital game-based learning. ACM Computers in Entertainment, $1(1), 1-4$.

Scaico, P.D., Marques, D.L, Azevêdo, M.A Silva, J.C. Neto, S.V.M. (2011). "Combinando Diversão e Educação: Castelo dos Enigmas, um Jogo Sério para o Ensino de Algoritmos”. XXII SBIE - XVII WIE.

Sheppard, B. (2000). The 21st century learner: premises and goals.

Tenório, R.(2001). Computadores de Papel - Máquinas abstratas para um ensino concreto, São Paulo, Editora Cortez, $2^{\mathrm{a}}$ Edição. 